\title{
O letramento acadêmico na formação continuada: constituição de autoria e construção de identidades
}

Dorotea Frank Kersch

\section{Resumo}

O professor de língua portuguesa tem seu dia a dia marcado pelo trabalho com textos de diferentes gêneros; porém, são poucas as práticas sociais de que participa que o levem a consumir ou produzir textos acadêmicos. Neste artigo, refletimos a respeito do processo de letramento acadêmico de duas professoras, que participaram de uma formação continuada, a qual ajudamos a coordenar. No âmbito dessa formação, foram desafiadas a produzir um artigo científico em que refletissem sobre sua prática. Analisam-se os dados gerados em uma reunião de discussão dos textos produzidos pelas professoras, bem como esses textos. Os resultados mostram que, ainda que as professoras não dominassem o gênero, o espaço de discussão que se abriu, com orientações para a reescrita, contribuiu para que elas se engajassem de forma efetiva na tarefa e conseguissem produzir o artigo, assumindo-se como autoras e construindo nova identidade, a de pesquisadora.

Palavras-chave: Letramento do professor. Artigo científico. Identidade. Formação continuada.

\section{Introdução}

Freire (2001, p. 260), em sua Conversa com Professores, afirma que "Há sempre algo diferente a fazer na nossa cotidianidade educativa, quer dela participemos como aprendizes, e portanto, ensinantes, ou como ensinantes e, por isso, aprendizes também”. E disto que queremos falar neste artigo: de quando o professor, na formação continuada, torna-se aprendiz e constrói nova identidade: a de pesquisador.

Na sociedade letrada contemporânea, estamos todos envolvidos num conjunto de práticas sociais que envolvem textos de diferentes naturezas. Os textos são concebidos num processo dialógico, estão

Professora do Programa de Pós-Graduação de Linguística Aplicada da Universidade do Vale do Rio dos Sinos (Unisinos). E-mail: doroteafk@unisinos.br.

Data de submissão: mar. 2014 - Data de aceite: abr. 2014 http://dx.doi.org/10.5335/rdes.v10i1.4096 
sempre sendo (re)feitos a cada nova leitura, porque estão em constante diálogo, e, nesse movimento, são questionados, aceitos, criticados, absorvidos, (re)significados. É nessa perspectiva que entendemos o letramento como um conjunto de práticas sociais, orais ou escritas, que envolvem essa dinâmica de produzir textos de diferentes gêneros, os quais movimentam a sociedade, dando-lhe vida.

A participação efetiva e ativa nas mais diferentes esferas leva-nos a produzir textos de diferentes gêneros. Ao agir na sociedade, consumindo e produzindo gêneros, instauram-se relações de poder, constroem-se e negociam-se identidades. $O$ trabalho com gêneros, nessa perspectiva, é visto como espaço de constituição e diálogo de culturas e identidades, consequentemente, passa a ser também espaço de manutenção (ou subversão) de uma ordem: da professora que, na perspectiva freireana, passa de ensinante a aprendiz.

Desde 2010, vimos trabalhando, numa parceria do PPGLA da Unisinos e a Secretaria Municipal de Novo Hamburgo-RS, com os professores daquela rede municipal, em projeto $^{1}$ que tem o apoio do Programa Observatório da Educação. Esse projeto se propõe a produzir conhecimento e interagir no processo educativo de leitura e produção escrita do sistema formal de ensino.

No âmbito desse projeto, temos desenvolvido uma metodologia de trabalho que denominamos Projeto Didático de Gênero (PDG), que como se verá adiante, pre- vê uma produção inicial, a partir da qual o professor faz o diagnóstico da turma, prevê a oferta de oficinas, a construção da grade de avaliação, a produção final, e a reescrita. Todo PDG, é claro, precisa estar vinculado a uma prática social, os textos lidos precisam ser reais, e os que serão produzidos precisam ser lidos por diferentes pessoas, além do professor.

Desenvolver esse tipo de trabalho com os alunos já passou a fazer parte da rotina dos muitos professores que participaram da formação continuada. Mas e quando o professor passa por esse processo? O que acontece quando o professor é convidado a refletir a sua prática na forma de um artigo científico que será publicado em livro (e esse livro será lido por outros professores)? Essas perguntas levam-nos ao objetivo deste artigo, que é refletir sobre o processo de letramento acadêmico de duas professoras bolsistas, integrantes do projeto a que nos referimos, quando levadas a participar de práticas acadêmicas que não lhe eram familiares, principalmente depois de concluída a graduação.

$\mathrm{Na}$ sequência, encontra-se a base teórica que sustenta este estudo, a metodologia usada para a geração dos dados, seguida da análise e da discussão dos resultados.

\section{Fundamentação teórica}

Desde a década de 1980, com a obra de Mary Kato, No mundo da escrita: uma perspectiva psicolinguística, o termo letramento tem integrado a produção científica 
brasileira e, posteriormente, alcançado as escolas, por meio de vários programas do governo, muito em função de as avaliações em larga escala (Prova Brasil, PISA, ENEM, por exemplo) estarem mostrando nossa ineficiência em ensinar nossos alunos a ler e escrever, capacitando-os para, por meio da leitura e da escrita, participarem das diversas práticas sociais que requerem esses conhecimentos.

Entendendo letramento como um processo de aquisição da leitura e escrita (e da oralidade) ao longo de toda a vida, cabe a discussão aqui do desenvolvimento do letramento acadêmico de duas professoras, ocorrido no âmbito de uma formação continuada. Procuramos compreender como elas fazem uso da leitura e da escrita, não somente no seu dia a dia, porque isso fazem, afinal, são professoras de português, mas também fora do seu ambiente de trabalho, num outro espaço, o acadêmico, em que não sejam tão somente consumidoras de gêneros, mas também produtoras, nesse caso em especial, do artigo científico. $\mathrm{Ou}$, parodiando Soares (1998), compreender como vivem o estado ou condição de quem sabe ler e escrever e pratica a leitura e a escrita, fora do espaço que lhe é mais familiar - a escola.

O letramento, conforme Barton e Hamilton (2000), constitui um conjunto de práticas sociais que as pessoas são capazes de executar; por essa razão, também está ligado a relações de poder e à construção de identidades. Se entendemos o letramento acontecendo no âmbito de práticas sociais, podemos perceber com mais clareza sua função e seu papel na constituição dos indivíduos (e eles se constituindo na e pela linguagem). Entendemos, portanto, letramento como aquilo que as pessoas fazem com a leitura e a escrita no seu dia a dia.

Street (1984) propôs a existência de dois modelos de letramento: como um conjunto de competências de natureza genérica, aplicável a uma grande diversidade de contextos, que denominou letramento autônomo; ou como prática situada, indissociável dos contextos sociais em que as práticas se desenvolvem e pressupõem usos específicos da linguagem veiculados por gêneros textuais próprios, o chamado por ele de letramento ideológico.

Quem se filia ao modelo autônomo, vê o letramento como competência individual e descontextualizada, que, adquirida, passa a ser transferida e aplicada a outros contextos. Por outro lado, filiar-se ao modelo ideológico é compreender leitura e escrita como práticas sociais, culturalmente determinadas. De acordo com essa última perspectiva, o letramento varia de uma cultura a outra.

Assumindo a perspectiva do modelo ideológico de letramento neste estudo, afirmamos, então, que há inúmeras práticas de leitura e escrita, próprias do ambiente escolar (elaboração de plano de aula, elaboração e correção de provas, chamada, participação em reuniões, etc.) com que o professor está bastante familiarizado. Como professor de língua 
portuguesa, também é comum que proponha a produção de textos de variados gêneros e de diferentes domínios discursivos. Ter as habilidades desenvolvidas para essas atividades, entretanto, não o habilita, per se, a transitar por outras esferas, como a acadêmica, na qual outros gêneros e outras linguagens sociais (GEE, 2001) circulam.

$O$ letramento acadêmico de que tratamos neste artigo diz respeito à fluência em formas próprias de fazer, ler, escrever, pensar, falar e agir, muitas delas características desse contexto social. Ele é o resultado de um processo de desenvolvimento de habilidades e percepções referentes às formas de interagir com a escrita nesse domínio social; a história do letramento de cada indivíduo e as representações construídas ao longo dessa trajetória, entretanto, não podem ser desconsideradas, uma vez que todo esse conjunto de influências levará o professor a se apropriar do discurso acadêmico.

Lea e Street (1998) apresentam três abordagens por meio das quais a escrita acadêmica pode ser compreendida: modelo dos estudos de habilidades, modelo da socialização acadêmica e modelo do letramento acadêmico.

De acordo com a primeira abordagem, o letramento é entendido como um conjunto de habilidades individuais e cognitivas que os estudantes precisam adquirir e desenvolver. Adquiridas, essas habilidades seriam transferidas a outros contextos de escrita da universidade. No modelo da socialização acadêmica, o professor é quem vai introduzir os alunos na cultura universitária, de forma que se apropriem dos modos de falar, raciocinar, interpretar e escrever nas disciplinas e temas próprios dessa instituição. Dentro desse modelo, gêneros discursivos acadêmicos são relativamente homogêneos e, aprendendo convenções que regulam esses gêneros, conseguirão participar das práticas letradas próprias dessa esfera. Já a última abordagem entende os letramentos como múltiplos, como práticas sociais e, nesse sentido, constituem o fazer da esfera acadêmica, e constituem uma outra forma de compreender, interpretar e organizar o conhecimento. Esse modelo se foca nos significados que os indivíduos atribuem à escrita, desde as questões epistemológicas que essa envolve, até as relações de poder entre instituição, professores e alunos, as identidades sociais e a história de letramento de cada um.

Essas abordagens, evidentemente, não se excluem, uma vez que, para conseguir produzir gêneros da esfera acadêmica, é necessário dominar as convenções da língua, apropriar-se dos discursos valorizados pela universidade, mas, acima de tudo, não se pode ignorar as trajetórias individuais de letramento.

Falar de letramento é, pois, falar de agir no mundo, não de uma habilidade neutra ou de uma técnica aprendida pela repetição, descolada da realidade e esvaziada de sentido. A universidade, seja na formação inicial ou na continuada, é um espaço organizado por diversas práticas sociais, em que professores e 
alunos, sujeitos letrados, mostram como se relacionam com a escrita. No âmbito dessas práticas, abre-se a possibilidade de construir novas relações e, nas interações nesse domínio social e discursivo, novas identidades são negociadas.

Gee (2001) argumenta que algumas pessoas não conseguem se inserir e desempenhar funções em determinados contextos em razão de que não foram expostas a determinadas atividades em períodos anteriores da vida. Nesse sentido, denomina outsider esse indivíduo que não consegue se inserir ou não se sente inserido em determinados domínios. Para se tornar insider, é necessário que o sujeito seja imerso em contextos específicos de uso da língua, e que seja levado a participar de processos de socialização, o que não significa, necessariamente, receber instrução formal a respeito (por isso afirmamos que o letramento acontece também fora das instituições de ensino, embora elas sejam ainda a principal agência de letramento).

O uso, as práticas sociais, a necessidade levam à apreensão de um gênero. Por essa razão, é possível ter bom domínio da língua, mas não ser capaz de produzir textos de determinado gênero, de tomar turnos, de interagir com desenvoltura. Bakhtin afirma que:

São muitas as pessoas que, dominando magnificamente a língua, sentem-se logo desamparadas em certas esferas da comunicação verbal, precisamente pelo fato de não dominarem, na prática, as formas do gênero de uma dada esfera (2003, p. 303).
Isso nos faz assumir o modelo de letramento acadêmico como prática social (LEA; STREET, 1998), uma vez que é nessa perspectiva que várias questões são consideradas, tanto as epistemológicas quanto os processos sociais. Por conta das questões epistemológicas, essa abordagem de letramento acadêmico leva em conta a natureza, as bases e a validade do conhecimento, estando ligada à construção do sentido, da identidade, do poder (uma vez que capacita para a ação).

\section{Metodologia}

Janete e Tatiane ${ }^{2}$ são duas professoras da rede municipal de Novo Hamburgo-RS. Ambas foram bolsistas no âmbito do projeto a que nos referimos antes. Têm ainda em comum certa inquietude e grande vontade de estudar, aprender e fazer diferente. Janete é professora do terceiro ano, Tatiane, do quinto. Elas desenvolveram PDGs entusiasticamente com seus alunos e, ao sentirem-se desafiadas, resolveram escrever um artigo científico, refletindo sobre sua prática, para ser publicado em um livro organizado pelas pesquisadoras do PPGLA. Ambas sabem que, na concepção freireana, não existe ensinar sem aprender. Mesmo que essa aprendizagem possa ser dolorida, como se verá adiante.

Nossa comunidade de indagação (KERSCH; GUIMARÃES, 2012) reúne-se todas as terças pela manhã, senta-se ao redor de uma mesa oval (para que to- 
dos fiquem na mesma posição) e estuda, discute, dialoga, planeja, avalia. Para que todos se apropriassem dos conceitos que sustentam o projeto, foram lidos artigos científicos referentes a temáticas que fariam um alinhamento conceitual (concepção de linguagem, educação linguística, letramento, sequência didática, gêneros textuais, por exemplo). Então, como Janete e Tatiane já haviam lido vários artigos científicos na comunidade de indagação, partimos do princípio de que elas tinham ideia do que seria a estrutura de um artigo científico (a linguagem social dessa esfera). Nesse sentido, seguindo a metodologia do PDG, foi-lhes solicitada a produção inicial.

Em seguida, se esta fosse uma atividade regular de sala de aula, após a produção inicial e a realização de oficinas, o texto seria lido por outros colegas. Nessa atividade específica, tivemos a participação de uma professora do curso de Letras da Unisinos, que ministra a disciplina de escrita acadêmica. Ela ofereceu uma oficina e deu as orientações em relação à estrutura do texto científico, analisando um artigo com o grupo. A partir dessa oficina, Tatiane e Janete fizeram a primeira avaliação de seus textos, que foram, então, enviados a todos os integrantes do grupo para que, numa atitude responsiva ativa, tivessem as ideias discutidas, aceitas, alteradas, suprimidas.

$\mathrm{Na}$ reunião presencial da semana seguinte, tomando por base a oficina de que participaram e analisando outros artigos, construiu-se, com todo o grupo, a grade de avaliação, para que nova análise fosse realizada pelas autoras, no intuito de que pudesse ser encaminhada a reescrita do texto. Os dados gerados e que são analisados e discutidos na sequência são resultantes dessa reunião de avaliação, na qual as diferentes versões dos textos de Tatiane e Janete foram discutidas, tendo os comentários acerca dos trabalhos sido transcritos. Na ocasião, foram, também, compartilhados o conteúdo dos e-mails trocados com a coordenadora da atividade. Assim, nessas idas e vindas dos textos produzidos por elas, novas identidades se construíram.

\section{Resultados e discussão}

O professor está familiarizado com algumas práticas. Participa, no seu dia a dia, de eventos de letramento específicos, tais como escolher livro ou material didático, planejar aulas, ministrar aulas, fazer chamada, enviar bilhetes para os pais, fazer atas de reuniões, participar de formações e assim por diante. Nesses eventos, circulam gêneros dos quais se apropria e que lhe acabam sendo familiares. Entendemos, entretanto, que embora leitura e escrita de gêneros acadêmicos (dissertações, artigos, ensaios, etc.) não façam parte de seu dia a dia, é fundamental que ele seja encorajado a fazê-lo (desde que, evidentemente, alguma prática social requisite essa leitura e/ou escrita).

Nos termos de Gee (2001), para tornar nossas professoras insiders de um espaço que lhes era estranho, elas tiveram a oportunidade de, na comunidade 
de indagação, ler diferentes textos do gênero artigo científico, publicados em periódicos e em livros. Entretanto, o desenvolvimento do letramento acadêmico é uma caminhada longa e difícil para todos que se envolvem nessas práticas. Ler gêneros acadêmicos requer alguma habilidade e, escrever, requer outras tantas que o professor pode não ter tido a oportunidade ainda de desenvolver.

No caso da formação que oferecíamos, era preciso fazer o professor a ensinar a si mesmo a ler e a escrever para agir no mundo: escrever para refletir sobre o seu trabalho, para que seus colegas lessem. No caso de Janete e Tatiane, ainda que ambas fossem formadas em Letras, trabalhassem a produção escrita de seus alunos, na formação, assumiam outro papel social, outra identidade, na qual, do mesmo modo que os alunos, também eram aprendizes e confrontavam-se com a folha em branco. Dominar a língua não significava dominar o gênero. Rapidamente deram-se conta de que era preciso deixar de ser outsider e tornar-se insider.

É no seio das práticas que a identidade de professora - que corrige o texto dos outros, que dá palpites de como os alunos podem iniciar seu texto - passa à de pesquisadora, que toma a palavra, que discute, que constrói conhecimento. Ela precisa tomar decisões para que o seu texto tenha as características do gênero solicitado:

[...] mas a minha preocupação inicial foi colocar a ideia no papel para não escapar o fio que eu queria seguir, então, eu fui colocando, né (...), mas minha preocupação mesmo nesse momento foi por onde eu vou começar, eu me senti desafiada, porque também eu tive até muito pouco tempo, porque a gente tava fechando notas na escola (Tatiane, professora bolsista).

As duas identidades estão presentes na fala de Tatiane: a de professora, com as tarefas da escola (que também oscila entre a identidade individual "eu", "minha" e "a gente", esta última coletiva, pela qual estende a seus colegas a realidade em que vive); e a de pesquisadora, que precisa ter um fio condutor para seu artigo. Nossa convivência com as professoras (não só essas, mas as de outras pesquisas também) tem nos mostrado mulheres em seu trabalho solitário, o qual consome seu tempo na rotina, e pouco (ou nenhum) tempo sobra para investir no seu crescimento, na sua formação, no estudo propriamente dito.

Janete e Tatiane tinham consciência de que os textos produzidos precisavam assumir uma função social própria (precisavam auxiliar outros professores e pesquisadores a compreender a realidade em que a experiência desenvolvida com o PDG seria relatada), transformando-se em troca, em compartilhamento, em debate de ideias.

Trabalhar com PDG tem nos mostrado que, desafiados, seja aluno, seja professor, os sujeitos se superam. Assumem a palavra. Na "vida real", não escrevemos para receber nota, para cumprir uma tarefa, mas escrevemos para sermos lidos, criticados, complementados, para que nos respondam que concordem ou discordem do que dissemos. E, nesse 
processo dialógico, o texto vai se constituindo. Tatiane foi a primeira leitora de seu próprio texto. Depois, ouviu o que os colegas acharam e, então, lançou outro olhar sobre ele:

Hoje, lendo, eu vejo que tem coisas berrantes aí pra arrumar. [...] a gente vai trabalhando nele ao longo de um tempo, pra que ele fique bem conciso, fique encorpado, tenha as características do próprio gênero, então, falta muito ainda [...] (Tatiane, professora bolsista).

Escrita é processo. Até chegar à autoria, há muito trabalho envolvido. Tatiana, com a identidade de professora de português, sabe que o texto precisa ficar conciso e encorpado, como ela diz. A pesquisadora Tatiane analisa seu texto e vê que apenas começou, pois 'tem coisas berrantes para arrumar'. Janete, por sua vez, vê a tarefa de escrita acadêmica, não somente difícil, mas dolorida: "eu não vejo como difícil, eu vejo como dolorido, é muito dolorido escrever, principalmente quando tu não sabe" (Janete, professora bolsista).

A tarefa de escrita não é fácil para ninguém, tampouco para Janete, o que é, segundo ela, acentuado quando não se sabe como fazê-lo. Desenvolver o letramento é processo para toda vida. É óbvio que Janete sabe escrever, mas, como nossos atos de linguagem materializam-se por gêneros, há alguns que ela não domina e vai ter de aprender a construir.

Mesmo que a experiência não seja a primeira, a dificuldade não diminui:

Eu já fiz um artigo, mas me parece que essa situação de escrever um artigo prum livro é muito dolorido, porque tu tá te expondo totalmente ali, e não expondo somente a ti, é diferente tu escrever um artigo onde tu vai mostrar prum professor ali, tu tá expondo um grupo, é um grupo de professores, pesquisadores (Janete, professora bolsista, ao falar sobre seu processo de escrita do artigo).

O que Janete destaca como reforçador da dor de escrever é o fato de a identidade da pesquisadora tornar-se coletiva, já que pertence a um grupo (tu tá expondo um grupo). Não é apenas um EU se manifestando. É um NÓS. Não é mostrar o resultado de seu trabalho para uma colega, é publicar, e aí o texto vai dialogar com outros, suas ideias já não serão mais suas, porque outros vão apropriar-se delas, vão ser discutidas, receber acréscimos, concordâncias, discordâncias. Nesse ir e vir, culturas dialogam, identidades se constituem, conhecimento se constrói.

Analisando o processo, percebemos que, no espaço da formação continuada, ainda que o imaginássemos colaborativo e achássemos que estávamos sempre abertas ao diálogo, que tínhamos uma relação amigável e interativa, em que construímos, com as professoras, o conhecimento o modelo de letramento acadêmico (LEA; STREET, 1998) que acabou prevalecendo foi o da socialização acadêmica (afinal, estávamos trabalhando vários artigos que poderiam servir de modelo para elas replicarem) e o de estudo de habilidades (eram professoras de português, logo, "sabiam a língua").

Tal como na sala de aula do ensino superior, em que o professor solicita que os alunos façam uma resenha, um fichamento, um artigo, sem eles terem, 
muitas vezes, ideia do que isso exatamente significa, de como esse gênero é estruturado, lá estávamos nós repetindo o modelo: façam um artigo, cuja atividade, claro, passa a ser dolorida para elas. Elas (como, muitas vezes, seus alunos) não tinham uma concepção clara do que significava aquele gênero. Foi nesse contexto de dúvidas em que Janete promoveu a produção inicial:

A escola, através dos educadores, deve cada vez mais refletir sobre o seu papel social e procurar desenvolver habilidades argumentativas, sejam elas orais ou escritas, e também possibilitar aos educandos a aprendizagem de diferentes gêneros textuais e práticas de linguagens dento de uma perspectiva sociointeracionista, adotando a oralidade como objeto de ensino (parágrafo introdutório do artigo científico de Janete).

Ao lermos esse parágrafo, perguntamos-nos: que representações Janete tem do gênero? Está certo que ela tem várias habilidades desenvolvidas, seu texto, a grosso modo, está gramaticalmente correto, mas onde está a voz de Janete? O que ela tem a dizer a seus pares? Essa, contudo, foi a primeira versão de seu texto, o qual ela submeteu à leitura do grupo, afinal, ela tinha um espaço que dava eco à sua voz, pessoas que queriam realmente saber o que ela queria dizer, assim, a partir das oficinas, seu texto foi ganhando forma, e ela se constituindo autora.

$\mathrm{O}$ fato de ter um espaço no qual os textos de diferentes gêneros são lidos, discutidos, avaliados, também fica marcado na fala de Tatiane:
Meu caso é bem inicial e tem muito que melhorar eu preciso agora desse tempo pra ir ajustando, e as sugestões de hoje vão ser fundamentais pra esse caminho, ser melhorado até a produção final, né, pra chegar a um consenso" (Tatiane, após seu texto ter sido discutido e avaliado).

Após a reunião de discussão, parece que ambas compreenderam o que significa ter uma atitude responsiva ativa diante de um texto. Janete também opina:

E como organizar isso, né, de uma maneira que tenha uma sequência, que a tua lógica possa contribuir pra que o outro vá ler e acrescentar algo mais, né, é uma preocupação constante, como eu disse na semana passada, é um esboço, no meu caso, a produção inicial é um esboço (Janete, professora bolsista).

Entre idas e vindas, Janete chega à produção final:

Iniciei o ano de 2012 , nesta turma do $3^{\circ}$ ano, ouvindo relatos diários de cenas de violência presenciadas pelas crianças. A cada dia mais e mais notícias de mortes, assaltos e ameaças que envolviam o cenário do bairro em que a escola em que trabalhava estava localizada em consequência de brigas entre gangues rivais pelo controle do tráfico. Muitos alunos tinham vizinhos, amigos ou até mesmo parentes entre as vítimas e via-se claramente que estavam aterrorizados pelo medo e pela insegurança (Primeiro parágrafo do artigo de Janete, na sua versão final).

Da primeira à última versão, vê-se o claro crescimento de Janete. Na sua última versão, escreve em primeira pessoa, assume-se como autora (diferentemente da primeira versão, em que juntou algumas expressões do senso comum e tentou dar forma, usando a terceira pessoa). Parece que Janete era o tipo de leitor para quem, segundo Marinho (2010, 
p. 370), "O discurso acadêmico se sustenta por estratégias elaboradas de erudição pouco compreensíveis e usuais para um leigo", logo, também ela escreveu algo pouco compreensível, que pouco dizia. Assim, representação que tinha da escrita acadêmica era que essa deveria ser empolada, difícil de compreender.

\section{Considerações finais}

Olhando para o processo de letramento acadêmico de Janete e Tatiane, percebemos que, ao oportunizar ao professor a escrita de gêneros acadêmicos, como artigos científicos, oportunizamos, no âmbito da formação continuada, que elas não apenas executem um plano que lhes foi dado previamente (como acontece no dia a dia da maioria dos professores, que têm seu trabalho prescrito pelo planejamento da escola, pelo livro didático), mas que reflitam sobre a forma de seu agir, atribuindo sentido ao que fazem, capacitando-as a auxiliar seus alunos a fazerem o mesmo.

Cada um de nós é desafiado quando está diante do novo, diante de um gênero nunca produzido. É o que provavelmente acontece com nossos alunos, quando se veem diante dessa tarefa. Falta dar a quem produz textos - alunos e professores - as orientações adequadas e completas, acesso a vários textos do gênero, para que analisem, comparem, percebam a estrutura, a linguagem social da esfera em que esse gênero circula. Muita vezes, falta trabalho efetivo com o gênero antes de chegar à produção.
O professor é sujeito ativo na construção de sua formação, mas, para que se assuma como tal, o desejo de aperfeiçoar-se tem de partir de si próprio. No caso da formação que ajudamos a coordenar, é por meio da cooperação, na interação com os integrantes do grupo, colegas e alunos, que os professores procuraram encontrar respostas e soluções para seus problemas. Foi a partir dessa tomada de posição, de apropriar-se da palavra, tornando-a sua, que Janete e Tatiane fortaleceram sua identidade de professoras e construíram a de pesquisadoras.

\section{Academic literacy in continuing education: building authorship and identities}

\section{Abstract}

The Portuguese language teacher spends his/her day working with different text genres. However, s/he has few opportunities to participate in social practices that involve consuming or producing academic texts. In this article, we reflect about the academic literacy process of two teachers who participated in a continuing education course we helped to coordinate. During the development of the course they were challenged to write a scientific text in which they should reflect on their own professional practices. We analyze the texts and the data resulted from a meeting where the texts are discussed. The results show that, even though the teachers do not have a full knowledge of this genre, the opportunities created under guidance for discussions and revision of the text contributed for the teachers' 
effective engagement in the task and enabled them to produce the required article, assuming its authorship and building for themselves a new identity as researchers.

Keywords: Teacher's literacy. Scientific Text. Identity. Continuing education.

\section{Nota}

1 Trata-se do projeto "Por uma formação continuada cooperativa: o processo de construção de objetos de ensino relacionados à leitura e produção textual", coordenado por Ana Maria Mattos Guimarães, no qual atuamos como pesquisadora associada.

2 Por princípios éticos, os nomes das professoras são fictícios, de modo que sua identidade seja preservada.

\section{Referências}

BAKHTIN, M. Estética da criação verbal. São Paulo: Martins Fontes, 2003.

BARTON, D.; HAMILTON, M. Local literacies: Reading and Writing in One Community, London/New York: Routledge, 2000.

BRASIL. Parâmetros Curriculares Nacionais: Língua Portuguesa. 3.ed. Brasília: Ministério da Educação e Cultura. Secretaria da Educação Básica, 1998.

BRONCKART, J. P. Atividade de linguagem, discurso e desenvolvimento humano. Campinas: Mercado de Letras, 2006.

O Agir nos discursos. Campinas: Mercado de Letras, 2008.

. Posfácio. In: ABREU-TARDELLI, L. S.; CRISTÓVÃO, V. L. L. (Orgs.). Linguagem e educação: o trabalho do professor em uma nova perspectiva. Anna Rachel Machado(Colab.). Campinas: Mercado de Letras, 2009. p. 161-174.
DOLZ, J.; GAGNON, R.; DECÂNDIO, F. Produção escrita e dificuldades de aprendizagem. Campinas: Mercado de Letras, 2009.

FRANZ, W. Prefácio à segunda edição. 2. ed. In: ANDRIOLI, A. I. Trabalho coletivo e educação. Ijuí: Ed. Unijuí, 2007.

FREIRE, Paulo. Pedagogia da autonomia: saberes necessários à prática educativa. São Paulo: Paz e Terra, 2001.

GEE, J. P. Reading as situated language: a sociocognitive perspective. Journal of Adolescent \& Adult Literacy, Newark, v. 8, n. 44, p. 714-725, 2001.

GUIMARÃES, A. M. M. Construindo propostas de didatização de gênero: desafios e possibilidades. Linguagem em (Dis)curso, v. 6, p. $4-12,2006$.

GUIMARÃES, A. M. M. et al. Por uma formação continuada cooperativa para o desenvolvimento do processo educativo de leitura e produção textual escrita no ensino fundamental. Projeto de Pesquisa, 2009 (mímeo).

KATO, M. No mundo da escrita: uma perspectiva psicolinguística. São Paulo: Ática, 1986.

LEA, M. R.; STREET, B. Student Writing in higher education: an academic literacies approach. Studies in Higher Education, Londres, v. 23, n. 2, p. 157-16, jun. 1998.

MARINHO, M. A escrita nas práticas de letramento acadêmico. $R B L A$, Belo Horizonte, v. 10, n. 2 , p. 363-386, 2010.

SOARES, M. Letramento: um tema em três gêneros. Belo Horizonte: Autêntica, 1998.

STREET, B. Literacy in theory and practice. Cambridge: Cambridge University Press, 1984. 